\title{
CONTROL OF INFLOW DISTORTION IN A SCARF INLET
}

Carl H. Gerhold

Senior Member, AIAA

Senior Research Scientist

Aeroacoustics Branch

Lorenzo R. Clark

Aerospace Engineer

Aeroacoustics Branch

Robert T. Biedron

Aerospace Engineer

Computational Modeling and Simulation Branch

NASA Langley Research Center

Hampton, Virginia 23681

The scarf inlet has the potential to reduce aircraft inlet noise radiation to the ground by reflecting it into the space above the engine. Without forward motion of the engine, the non-symmetry of the inlet causes inflow distortion which generates noise that is greater than the noise reduction of the scarf. However, acoustic evaluations of aircraft engines are often done on static test stands. A method to reduce inflow distortion by boundary layer suction is proposed and evaluated using a model of a high bypass ratio engine located in an anechoic chamber. The design goal of the flow control system is to make the inflow to the inlet circumferentially uniform and to eliminate reversed flow. This minimizes the inflow distortion and allows for acoustic evaluation of the scarf inlet on a static test stand. The inlet boundary layer suction effectiveness is evaluated both by aerodynamic and by acoustic measurements. Although the design goal is not met, the control system is found to have a beneficial effect on the engine operation, reducing blade stall and speed variation. This is quantified by two acoustic benefits, reduction both of the variability of tone noise and of the low frequency wideband noise due to the inflow distortion. It is felt that a compromise in the manufacture of the control hardware contributes to the inability of the control system to perform as expected from the analysis. The control system with sufficient authority is felt to have the potential

Copyright $(2002$ by the American Institute of Aeronautics and Astronautics, Inc. No copyright is asserted in the United States under title 17, U.S. Code. The U.S. Government has a royalty-free license to exercise all rights under the copyright claimed herein for Governmental purposes. All other rights are reserved by the copyright owner.

to permit reliable acoustic testing in a static configuration of engines with non-symmetric inlets. Because the control system can improve operation of the engine, it may also have the potential to reduce noise and vibration and enhance engine longevity during low speed ground operations in the terminal area.

\section{Introduction}

The scarf inlet is one in which the inlet lip protrudes more at the keel than at the crown. This design has the potential to reduce inlet radiated fan noise by redirecting a part of the acoustic energy up and away from observers on the ground. A computational analysis of the scarf inlet concept demonstrated that the scarf inlet may also have a reduced tendency to ingest foreign objects from the ground during takeoff and landing runs and can maintain attached internal flow at higher angle of attack than axisymmetric inlets. ${ }^{1}$

Several prototype scarf inlets have been fabricated for model and for full scale engine testing. The scarf inlet which is discussed in this paper was fabricated for the 12-inch diameter model fan engine and was tested previously in forward flow in the $14 \times 22$ foot VSTOL facility at NASA Langley Research Center. ${ }^{2}$ The experiment showed that the model engine equipped with a scarf inlet radiated less noise into the forward sector below the inlet than did the model when it was equipped with a symmetric inlet. The difference is fairly broadband, extending over $1 / 3$-octave bands from $2000 \mathrm{~Hz}$ to $15000 \mathrm{~Hz}$; and, although the difference is on the order of $0.5 \mathrm{~dB}$, the indication is that the scarf inlet does direct a portion of the acoustic energy away from the ground. The researchers note that the scarf angle, $10 i$, is relatively small and conclude that a more aggressive scarf design may 
provide more noise reduction. Because of safety issues and the high expense of flight testing, in situ validation of noise control technologies, such as the scarf inlet, is often done on a static test stand. A common problem that exists in static engine noise tests is that the engine is pulling air in from a quiescent medium and the turbulence that arises from the separated flow at the inlet lip is ingested, causing spurious noise to be generated, particularly at the blade passage frequency. The turbulence intensity is generally less once the aircraft is moving and so, in order to simulate forward flight, an inflow control device is utilized. The inflow control device is a large, hollow, removable sphere that can be rolled into place surrounding the inlet. It is fabricated from honeycomb material the cells of which are oriented along lines of potential flow into the inlet. The effectiveness of the inflow control device has been demonstrated for symmetric inlet designs. ${ }^{3}$ Despite the presence of the inflow control device, unexpectedly high blade passage frequency tones have been measured during acoustic tests on engines equipped with the scarf inlet, in full scale and model tests alike. A tone is generated sporadically at the blade passage frequency which indicates intermittent ingestion of turbulence. In addition, low frequency noise occurs at high fan speeds indicating onset of rotor stall. While the expectation is that the inflow distortion causing these tones will be decreased when the aircraft is in forward flight, the noise produced during the static test makes it difficult to assess the noise reduction performance of the scarf inlet. In addition, the noise and vibration induced by the inlet at low forward speed, such as during ground operation, could shorten the service life of the engine. Researchers at NASA Langley Research Center have undertaken to investigate the cause of the inflow distortion and to develop a control system using boundary layer suction to reduce the influence of the flow non-uniformity.

A computational study of the scarf inlet, verified by experiment, located the inlet separation on the half of the inlet centered on the crown. The analytical study further recommended introduction of boundary layer suction in the vicinity of the highlight. This modification was incorporated and evaluated in terms of its effectiveness both aerodynamically and acoustically.

Description of the Experiment The control system was developed on a 12-inch diameter model of a high bypass fan engine mounted in an anechoic chamber. The 12-inch Advanced Ducted Propeller (ADP) Demonstrator has 16 wide-chord rotor blades with hub to tip ratio of 0.445 . A row of 40 stator vanes is located 2 blade chords downstream of the rotors. This number of blades and vanes is used in order that the lowest mode of rotor/stator interaction noise is evanescent, ${ }^{4}$ and no tone at the blade passage frequency is expected to radiate. Figure 1 shows the 12-inch ADP Demonstrator with the scarf inlet in place. The model is powered by a 4-stage turbine which is driven by compressed air. The model is based on high bypass ratio, high subsonic tip speed engines. The rotor tip speed at $100 \%$ is subsonic at $905 \mathrm{feet} / \mathrm{second}$. The blade angle setting is fixed at the takeoff condition such that the fan pressure ratio is 1.27 at $100 \%$ speed. ${ }^{5}$ The model scarf inlet is equipped with two rows of static pressure taps extending from the inlet highlight to the rotor plane. One row is located at the crown of the scarf inlet, where the axial distance from the highlight to the rotor plane is minimum, and the other row is at the midpoint between the crown and the keel. Two boundary layer rakes are mounted near the rotor plane of the inlet, one at the keel and the other at the midpoint opposite the static array. The midpoint boundary layer rake can be seen in Figure 1, although it is removed for acoustic tests. Pressure data are collected on an ESP 8400 multi-channel pressure data acquisition system. In a typical data acquisition, the instantaneous voltage corresponding to pressure for all data channels is sampled 32 times and the average computed. Thirty-two (32) samples of the average pressures are written to a file, so that an average steady state pressure can be evaluated for each channel. The entire process of data acquisition takes approximately 8 seconds in real time.

Using the results of the CFD analysis which are presented in a later section, the scarf inlet was modified to allow for suction of air from the boundary layer in an area near the leading edge of the scarf inlet on the upper half (crown side). The recommended modification is a continuous slot approximately 0.5 -inch wide. Time and budgetary limits precluded fabrication of a continuous slot. Instead, eighty (80) holes were drilled through from the outside surface and 0.040 inch ID stainless steel tubing was bonded into the holes to make flush-mounted pressure ports. The 80 suction ports are distributed around half of the circumference centered on the crown of the scarf and are spaced on 0.238 inch centers, as can be seen in Figure 1. Each of the tubes connects to a proportional valve that can be controlled remotely. This arrangement was chosen to permit shaping of 
the suction contour around the inlet. The valves connect to a common manifold from which air is drawn by a PIAB Model 4000 vacuum pump. This type pump uses compressed air flowing through a series of nozzles to entrain air from the evacuated space. This type of vacuum pump is intended for applications requiring high flow rate and deep vacuum. The system was evaluated with the engine not operating, with all the valves fully open, and with maximum compressed air supply and was found to draw $27.6 \mathrm{cfm}$, so the pump was felt to provide sufficient flow rate for the control experiment.

All acoustic and aerodynamic testing of the model during this test were performed in the Anechoic Noise Research Facility at NASA Langley Research Center in Hampton, Virginia, although reference is made to tests performed previously on the model in the $14 \times 22$ foot VSTOL facility at NASA Langley Research Center. The anechoic chamber is a static facility, however, it is ventilated such that adequate flow is available to the fan to simulate an outdoor static test stand. The chamber s dimensions are 27.5 feet x 27.5 feet $x 24$ feet inside the acoustic wedges. The acoustic treatment is designed to absorb $99 \%$ of incident sound energy above $100 \mathrm{~Hz}$. Acoustic measurements are made using a hoop array on which are mounted 18 instrument-quality microphones on a diameter of 6 feet. The hoop can be rotated such that sound measurements are taken in the azimuth with resolution of $4 \boldsymbol{i}$, and the array can be translated to permit measurements on polar angles from $15 i$ from the engine axis to $90 i .{ }^{6}$ The microphones are Bruel \& Kjaer Model 4135, 1/4inch diameter. The microphone signals are conditioned first using Bruel \& Kjaer Model 2811 multiplexers, then using Precision Filters filter/amplifiers. The filters are set at $200 \mathrm{~Hz}$ highpass and $50 \mathrm{kHz}$ low-pass. Overall gain ranges from $8 x$ to $32 x$, depending on engine speed and array axial location. The data are recorded using a NEFF 495 high-speed multi-channel data acquisition system. In a typical data collection, 19 channels (18 microphones plus engine tachometer) of data are recorded for 4 seconds at a rate of 100 $\mathrm{k}$-samples/second. Data are archived daily using magnetic tape and optical disc. The microphone system is calibrated daily using a GENRAD Model 1986 Omnical electrostatic calibrator.

The model set up in the anechoic chamber with the hoop microphone array is shown in Figure 2. The inflow control device can be seen on the model. The acoustically treated wall surrounding the model is used to prevent aft-radiated noise from flanking into the inlet radiation sector.

Computational Investigation of the Scarf Inlet An analytical investigation of the aerodynamic performance of the scarf inlet was conducted in parallel with the experiments. Researchers from the Computational Modeling and Simulation Branch at NASA Langley Research Center performed a computational fluid dynamics (CFD) analysis of the inlet. Structured computational grids consisting of approximately 970,000 cells grouped into 4 zones were generated to model the inlet. Only the inlet geometry is modeled - the computational domain is truncated at the fan face. The spacing normal to the wall yielded an average $\mathrm{y}^{+}$of approximately 1.5 . Figure 3 shows the surface grid and exit face grid for the scarf inlet. The inlet orientation matches that used in a previous test, with the keel (long side) to the left and the crown (short side) to the right. All cases were run with a unit Reynolds number corresponding to 177,500. Simulations were performed as if the inlets were in free air; thus any wind tunnel wall effects are neglected. No-slip boundary conditions were used on all inlet surfaces. Because the loss of flow uniformity in the scarf inlet was observed to occur on the static engine, but it is not possible to run the simulation with precisely zero free stream flow, the static condition computations were run at a Mach number of 0.01 . This is the lowest Mach number that can be achieved in the simulation for which the solution converges. One case for the scarf inlet was run at a free stream Mach number of 0.15 in order to assess the effect of free stream velocity on the inlet flow. To model the variable engine settings used in the experiment, the pressure at the exit face of the computational grid was adjusted over a range of values of $\mathrm{P}_{\text {exit }} / \mathrm{P}_{\text {inf }}$ from 0.85 to 0.92 . The exit face of the grid corresponds to the input plane of the rotor. Note that this exit pressure was uniform in the simulation. An attempt was made to correlate the exit pressure used in the simulations with the engine settings used in the experiment, but the result was inconclusive because the pressure varies circumferentially in the scarf inlet. The pressure is relatively constant in an axisymmetric inlet which has been tested on the 12-inch ADP Demonstrator. In this case, the pressure range from 0.92 to 0.85 corresponds to the range of operating speeds from $80 \%$ to $100 \%$.

Figure 4 shows the near-surface streamlines for the scarf inlet at $\mathrm{M}=0.01$ with a back pressure of 0.92 . Streamlines colored red were introduced along the inside surface of the cowl, near the throat; 
streamlines colored blue were introduced along the outer surface of the cowl. Also shown in the figure are contours of axial velocity at the exit plane. Red indicates a positive axial velocity and the other colors indicate reversed flow. The streamlines inside the cowl on the crown side are seen to travel upstream to a point close to the inlet highlight, where the flow separates; while on the keel side (not visible in the figure), there is no evidence of separation. The transition where flow changes from downstream to upstream is at the midway point between the crown and the keel. A significant region of reversed flow is seen on the exit plane on the crown side. Similar results were obtained for other exit pressures, and the amount of reversed flow varied slightly with exit pressure setting. For the higher free stream Mach number (0.15), but with the same exit pressure, the scarf inlet exhibits no separation, as is shown in Figure 5. This is the expected result that forward motion will eliminate much of the inflow distortion in the scarf inlet.

The CFD model was modified to show the effect of introducing suction into the boundary layer near the inlet highlight. Figure 6 shows the results of analysis using suction over a strip near the highlight of the inlet covering one-half the circumference centered on the crown. The analysis shows that suction of air over this strip eliminates the flow reversal. The rate of suction from the analysis is $11.0 \mathrm{cfm}$ distributed uniformly over the strip. This flow rate is on the order of $0.08 \%$ of the flow through the fan.

\section{Experimental Results}

The 12-inch ADP Demonstrator tests in the anechoic chamber typically consisted of aerodynamic and acoustic data collection. Aerodynamic data consists of stagnation pressure measurements in the boundary layer near the entrance to the rotor and static pressure profiles on the inlet inner surface from the highlight to the fan face. The model is operated over a range from $70 \%$ to $100 \%$ corrected speed. The boundary layer rakes are removed and far field acoustic surveys are made for the model operating over the same range of speeds. Attempts were also made to visualize the inflow distortion and the flow visualization results are presented first.

Aerodynamic Results

Tinted oil was used to visualize the airflow in the inlet. Drops of oil were distributed around the inlet at the throat and the engine was run to speed. A typical sample of the oil flow visualization is shown in Figure 7. This figure shows the area of the midpoint between the crown (at the top in the figure) and the keel (at the bottom in the figure). The oil flow visualization shows that the air flows uniformly into the fan from the throat in the area toward the keel but is reversed in the vicinity of the crown and flows out of the inlet from the throat. The area in which flow is reversed extends circumferentially from the midpoint between the crown and the keel through the crown over to the midpoint on the opposite side of the inlet. The oil flow lines in Figure 7 are similar to the surface streamlines shown in Figure 4 from the computational analysis. The major difference is that the analysis assumes the flow velocity to be normal to the exit face and thus does not show the swirling due to rotation of the rotor.

Figures 8 and 9 show the boundary layer profiles from measurements on the scarf inlet. The profiles in Figure 8 are measured on the keel of the inlet at $100 \%$ speed (approximately $17300 \mathrm{rpm}$ ). Figure 9 shows the profiles at a point midway between the crown and the keel at $100 \%$ speed. In both of the figures, the pressure profiles measured with the model in the anechoic chamber are identified by $\mathrm{M}$ $=0$ with the boundary layer control either off or on. These profiles are compared to the results of measurements made previously in wind tunnel tests at external flow speeds of $\mathrm{M}=0.10$ and 0.15 , respectively. ${ }^{2}$ The pressure profiles show that going from forward flight to a quiescent medium causes the curves to shift to the right, which is felt to indicate a thickening of the boundary layer. The shift of the curves is more dramatic at the midpoint between the crown and the keel than it is on the keel. Similar boundary layer measurements were made during static tests on a Honeywell Model TFE731-60 engine with scarf inlet, ${ }^{7}$ although that test incorporated more boundary layer rakes around the inlet. The difference between the boundary layer profiles at the keel and at the midpoint from the full scale engine test are found to be similar to the differences between the $\mathrm{M}=0$ control off curves in Figures 8 and 9 , respectively. The boundary layer profile at the crown in the full scale engine test is farthest to the right, indicating that the boundary layer is thickest at the crown and that the thickness increases from the keel toward the crown.

The curves in Figures 8 and 9 that are designated $\mathrm{M}=0$ control on are the measured boundary layer profiles with the boundary layer control suction on. The air flow rate produced by the control system was $12.2 \mathrm{cfm}$ with the engine operating at $100 \%$ speed. Since it covers the crown half of the inlet, 
the suction system would not be expected to have much effect on the keel, and this is shown in Figure 8 . The desired effect of the control system is to produce a boundary layer profile in the vicinity of the crown that is similar to the profile produced in the wind tunnel simulating forward motion. Figure 9 illustrates that, although it has a measurable effect on reducing the boundary layer, the suction system lacks authority to simulate forward flight at the midpoint.

The flow control system produced the amount of suction that was required, according to the analytical model. However, the control system did not produce the desired effect of making the inflow to the fan uniform. Despite this fact, it was observed that the model fan ran more smoothly and with less tendency to stall at high speed with the boundary layer suction on than with it off.

Acoustic Results

Acoustic surveys were made of the inlet noise radiation to the acoustic far field of the 12-inch ADP Demonstrator with the scarf inlet and comparisons between control off and control on were made. A typical azimuthal radiation pattern of the sound in frequencies surrounding the blade passage frequency (BPF) tone when the model speed is set at $70 \%$ is shown in Figure 10. This plot is produced by integrating over the range of frequencies approximately $50 \mathrm{~Hz}$ below and above the blade passage frequency and it corresponds to $1 / 3$-octave band. The microphone array is located in the forward sector at an angle from the axis of the rotor of $70_{i}$, so the bottom microphones should be well within the shadow of the scarf. The figure shows the effectiveness of the scarf at reflecting sound upward, thereby reducing sound beneath the scarf. There is a slight clockwise shift in the pattern because of the rotor rotation. The sound level in the shadow of the scarf is 3 to $5 \mathrm{~dB}$ less than it is above the scarf. Measurements at other axial locations of the array indicate that the effect of the scarf diminishes further forward of the inlet, and the BPF sound level reduction is negligible at angles to the axis of less than $45 j$. Figure 10 shows that the sound level contour with the control system on is approximately the same as the contour with the control system off. This indicates that the control system does not degrade the acoustic performance of the scarf inlet. In fact, it was found that the effect of the boundary layer suction was negligible on the radiation of the blade passage frequency tone at all model speeds.
The control system is found to produce quantifiable effects in two areas of fan operation. One is to reduce the variability of the $\mathrm{BPF}$ tone and the other is to reduce the low frequency noise generation, both of which are felt to be caused by turbulent inflow.

When the incoming air stream through which the blade passage frequency tone propagates is turbulent, the sound that is radiated to the far field is unsteady. This unsteadiness can be quantified by evaluating the standard deviation of the blade passage frequency tone from the Fast Fourier Transform (FFT) of the time series. Each time series signal consists of 400,000 points. The FFT is 8192 point, with $50 \%$ overlap. Thus 95 spectra are evaluated from which the average and standard deviation are calculated. The tachometer signal is used to determine the blade passage frequency. Figure 11 is the standard deviation evaluated for all 18 of the microphones in the hoop array at one of the rotations for the engine operating at $97 \%$ speed. The standard deviation with control off is relatively constant over all the microphones in the hoop array, and the average of the standard deviations for the 18 microphones is $5.1 \mathrm{~dB}$. The standard deviation varies more widely around the inlet with the control on, but the average of all the microphones is less, $2.8 \mathrm{~dB}$. The range of average reduction of the standard deviation for all the measurements at $97 \%$ speed is from 0.5 to $2.5 \mathrm{~dB}$.

While the fan was operating at high speed with the control system turned off, the speed varied considerably, as much as $+/-100 \mathrm{rpm}$. Over the course of $1-1 / 2$ hours of continuous operation at $100 \%$ speed, the fan blades went into stall condition, characterized by a loud low frequency tone and large blade vibration, 9 times. No data were recorded until the fan recovered. When the control system was activated, the engine speed variability reduced by a factor of 8 to less than $+/-$ $12 \mathrm{rpm}$, and the fan blades did not go into stall over the period of operation of 1-1/2 hours. One way to quantify this effect is to evaluate the low frequency wideband noise radiation from the engine. The sound intensity is summed over the frequency bands from 500 to $3000 \mathrm{~Hz}$, and a typical curve is plotted for the array microphones in Figure 12. The control system is seen to reduce the wideband noise by from 0.7 to $1.5 \mathrm{~dB}$. It is also seen that the two curves are similar in form. Thus the radiation pattern of the low frequency noise is preserved when the control system is activated, which indicates that any low frequency noise reduction by 
the scarf inlet is not degraded by the flow control system.

\section{Conclusions}

The model fan with the scarf inlet ran poorly in the static test, even with the inflow control device installed. Engine speed variations were large at higher engine speeds, and the blades occasionally went into a stall condition. The boundary layer suction system was intended to reduce the circumferential variation of the inflow to the fan, thus simulating the forward flight condition. Despite the fact that the system lacked the authority to overcome the flow distortion caused by the scarf inlet, the flow control system was found to produce measurable effect on the engine overall performance. Most noticeably, the low frequency noise associated with blade stall is reduced by approximately $1.0 \mathrm{~dB}$, but the radiation pattern is preserved. This suggests that the control system does not introduce new noise sources.

The computational analysis indicated that the control system should be effective while drawing less than $1 \%$ of the engine flow out of the boundary layer. The control system was not as effective as expected, despite the fact that the design suction flow rate was met. It is felt that the shortcoming of the controller is due to the fact that the suction source is a finite number of discrete holes rather than a continuous slot. It is expected that, when the opportunity arises to modify the scarf inlet again, the discrete holes will be replaced with a slot more in keeping with the analytical model. This modification is expected to increase the control authority without necessitating increased flow rate.

Eliminating inlet flow distortion will allow static test stand acoustic evaluation of engines equipped with non-symmetric inlets such as the scarf inlet. This is useful to engineers during the developmental stages of noise control technology design. Inlet flow control may also enhance the performance of the scarf inlet by providing a means to reduce noise and vibration levels in engines with the scarf inlet during low forward speed operation of the aircraft. Reduction of vibration levels during ground operations could reduce wear on the engine and enhance passenger comfort.

References:

1. Abbott, J.M. and Slater, J.W., Computational

Study of the Aerodynamic Performance of Three-
Dimensional Subsonic Inlets, AIAA paper number 2001-3886.

2. Clark, L.R., Thomas, R.H., Dougherty, R.P., Farassat, F., and Gerhold, C.H., Inlet Shape Effects on the Far-Field Sound of a Model Fan, AIAA paper $97-1589$ presented at the $3^{\text {rd }}$

AIAA/CEAS Aeroacoustics Conference, May 1214,1997

3. Chestnutt, D., ed, Flight Effects of Fan Noise, NASA CP-2242, 1982

4. Tyler, J.M. and Sofrin, T.G., Axial Flow Compressor Noise Studies, SAE Transactions, vol. 70, pp 309-322, 1962

5. Hodges, R.M., Gerhold, C.H., Balster, D., and Thomas, R.H., Acoustic Testing of Very High Bypass Ratio Turbofans Using Turbine Powered Scale Models, AIAA Paper 94-2552, presented at the $18^{\text {th }}$ Aerospace Ground Testing Conference, June 20-23, 1994

6. Thomas, R.H., Farassat, F., Clark, L.R., and Gerhold, C.H., Azimuthal Patterns of the Radiated Sound Field from a Turbofan Model, AIAA paper 97-1588, presented at the $3^{\text {rd }}$ AIAA/CEAS Aeroacoustics Conference, May 12-14, 1997

7. Weir, D., private communication, 2000 


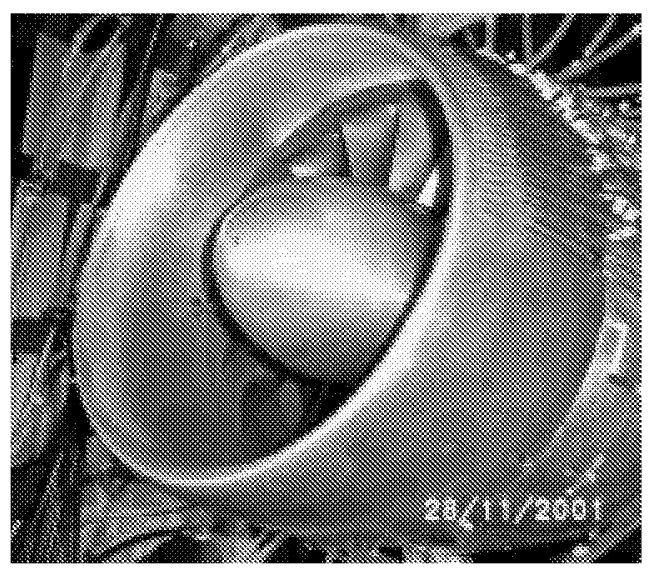

Figure 1. Scarf inlet modified for boundary layer suction over one half of the inlet centered on the crown

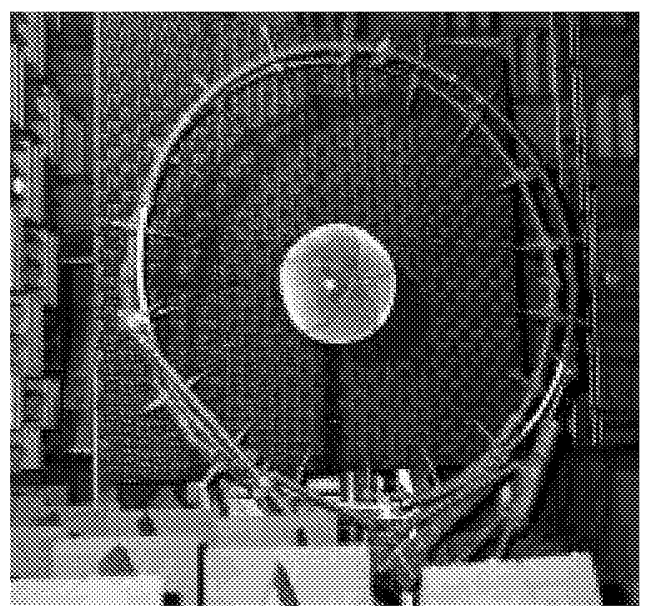

Figure 2. 12 inch ADP Demonstrator test set up in anechoic chamber with inflow control device and aft noise barrier. Microphone array shown in farthest forward position.

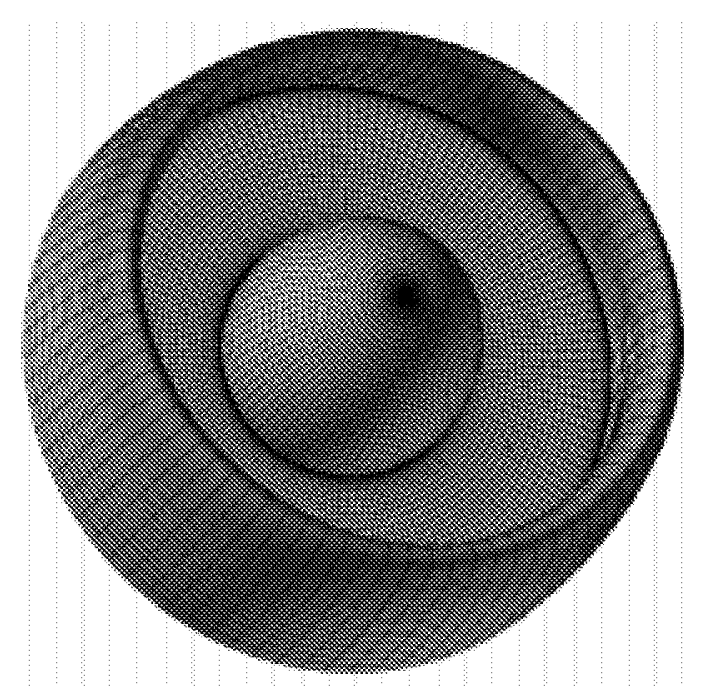

Figure 3. Surface grid for computational analysis of scarf inlet 

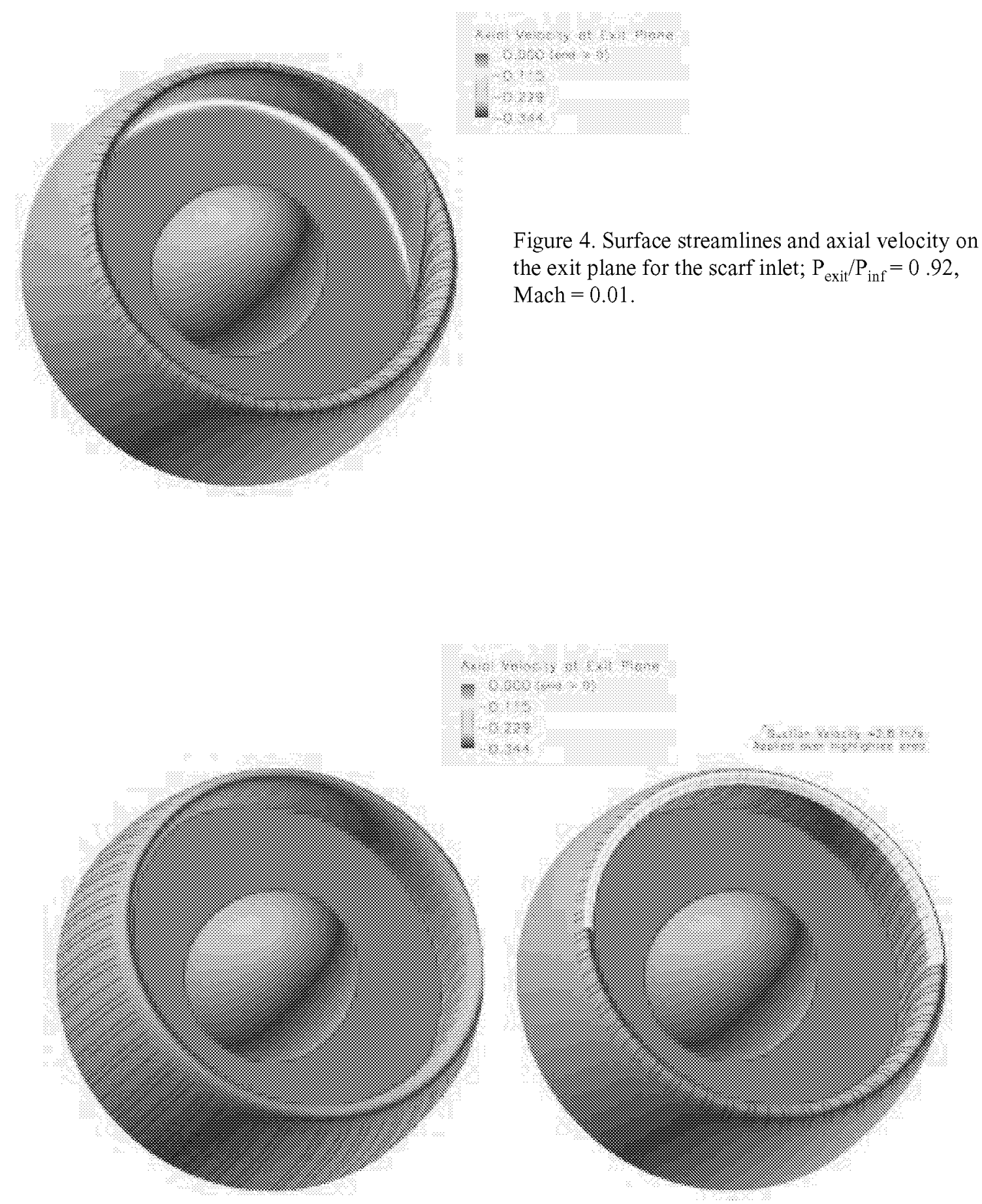

Figure 5. Surface streamlines and axial velocity on the exit plane for the scarf inlet; $\mathrm{P}_{\text {exit }} / \mathrm{P}_{\mathrm{inf}}=0$ .92 , Mach $=0.15$.

Figure 6. Surface streamlines and axial velocity on the exit plane for the scarf inlet; $\mathrm{P}_{\text {exit }} / \mathrm{P}_{\text {inf }}=0$ .92 , Mach $=0.01$, with suction applied over the region highlighted in white 


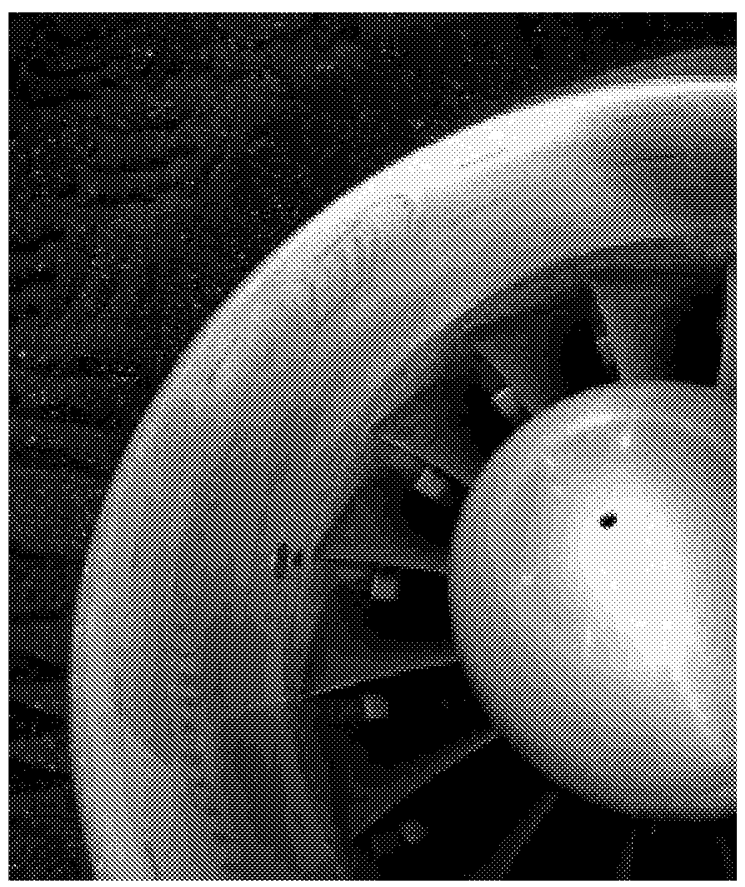

Figure 7. Oil flow test results from run at $90 \%$ speed. Location shown is midway between crown and keel

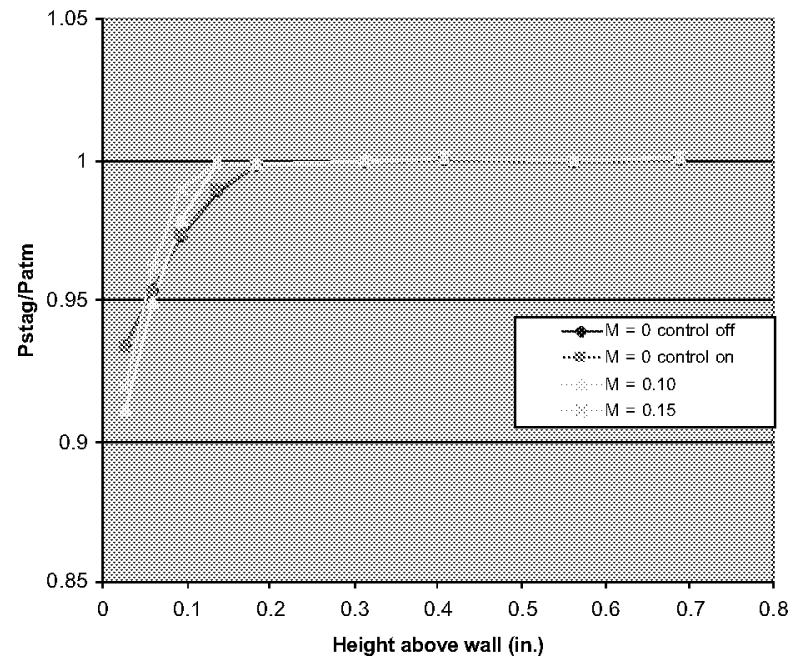

Figure 8 . Boundary layer profile on keel of scarf inlet at $100 \%$ fan speed.

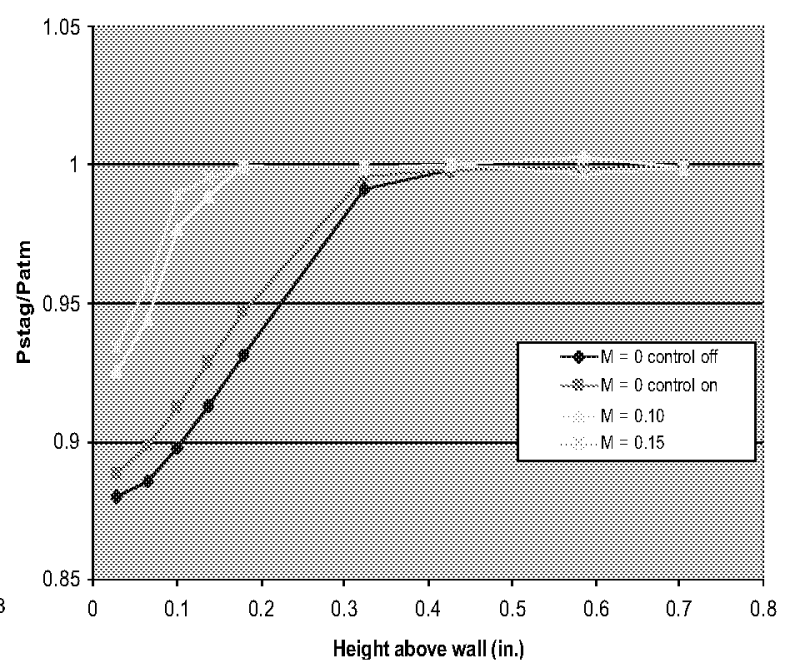

Figure 9. Boundary layer profile at midpoint of the scarf inlet at $100 \%$ fan speed. 


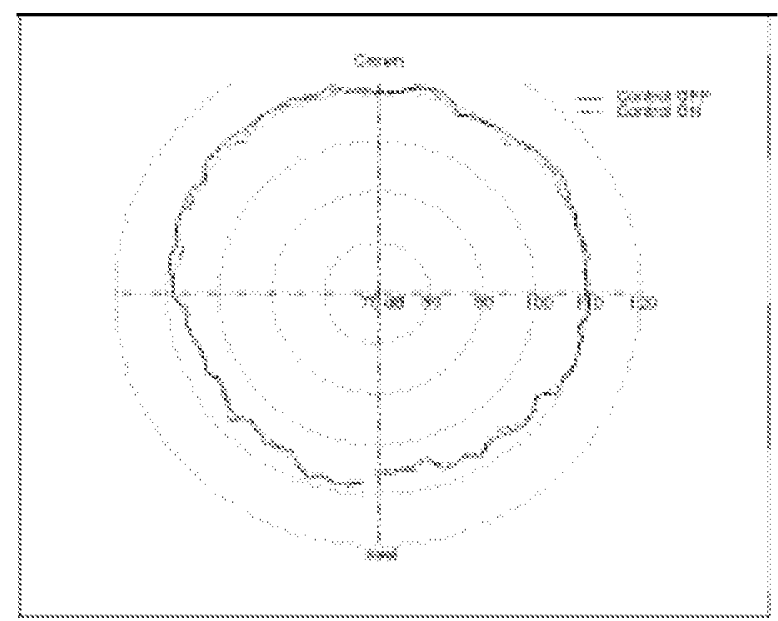

Figure 10. Contour of BPF tone from ADP Demonstrator with scarf inlet, at 70\% speed, $70 ;$ from fan axis.

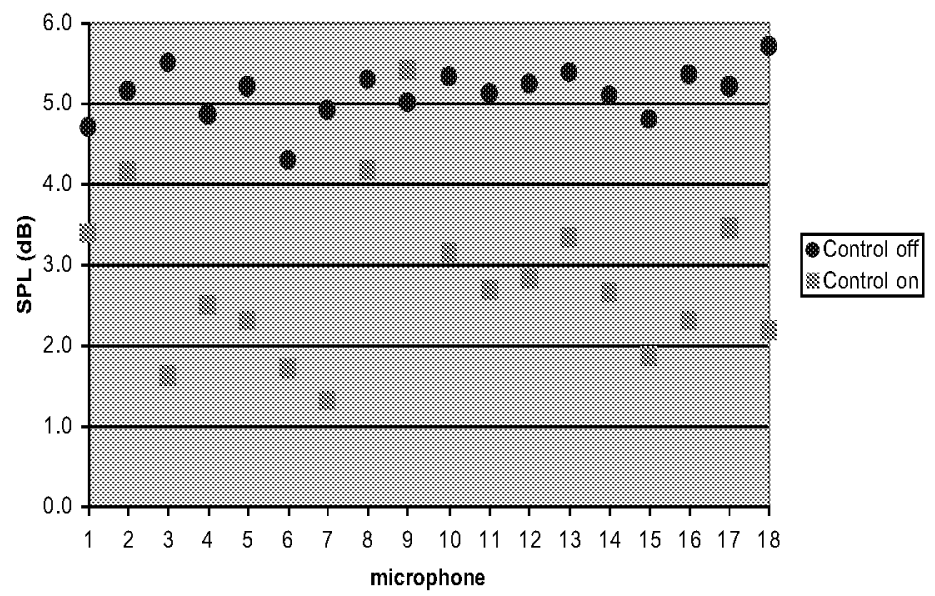

Figure 11. Standard deviation of BPF tone, ADP Demonstrator with scarf inlet at $97 \%$ speed, 70 from fan axis

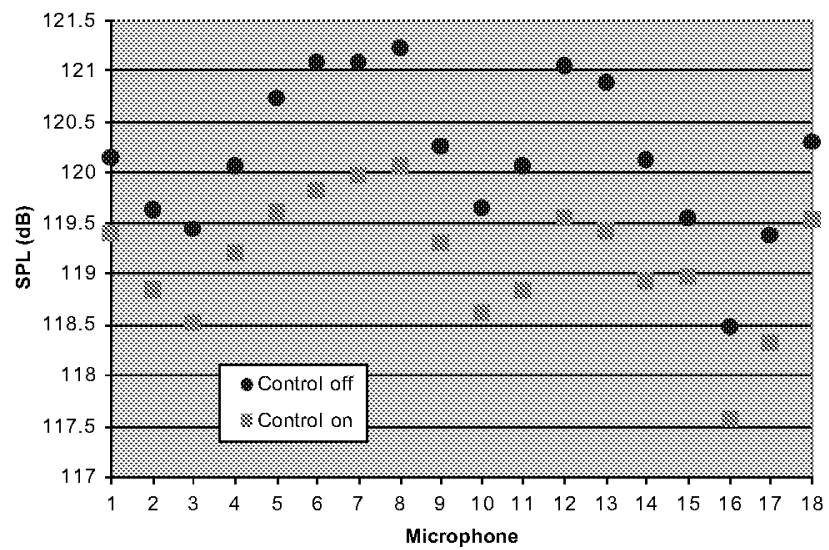

Figure 12. Wideband low frequency noise from ADP Demonstrator with scarf inlet at 100\% speed, 60 ; from fan axis. 